\title{
VISÃO DE PROFISSIONAIS E ESTUDANTES DA ÁREA DE SAÚDE SOBRE A INTERFACE SAÚDE E MEIO AMBIENTE
}

\author{
VIEW OF HEALTH AREA PROFESSIONALS ON THE INTERFACE BETWEEN HEALTH AND THE \\ ENVIRONMENT
}

\author{
Silviamar Camponogara ${ }^{1}$ \\ Cibele Mello Viero ${ }^{2}$ \\ Graciele Erthal ${ }^{3}$ \\ Paola da Silva Diaz ${ }^{4}$ \\ Gabriela Camponogara Rossato ${ }^{5}$ \\ Sabrina de Aguiar Soares ${ }^{6}$ \\ Roger Rodrigues Peres ${ }^{7}$
}

Resumo Este artigo apresenta a visão de profissionais e estudantes da área da saúde sobre a interface saúde e meio ambiente. Estudo de abordagem qualitativa, descritivo, desenvolvidos com diferentes atores sociais que integram o processo de formação profissional e laboral da área da saúde em um município do Rio Grande do Sul. Os dados foram coletados por meio de entrevista semiestruturada com questões norteadoras sobre o objeto de estudo, feita com trabalhadores hospitalares, enfermeiros, docentes, acadêmicos da área da saúde e agentes comunitários de saúde. Cada subprojeto foi analisado individualmente, com base no referencial sobre análise de conteúdo. Os resultados evidenciam que os sujeitos possuem visões dicotômicas sobre meio ambiente e reconhecem os efeitos prejudiciais da atual crise ambiental, alegando que o ser humano é o principal causador. Os sujeitos do estudo entendem que há estreita interface entre saúde e meio ambiente, sendo as populações menos privilegiadas economicamente as mais afetadas pelos danos ambientais. Conclui-se que o aprofundamento do debate sobre o tema no processo de formação e prática profissional em saúde é fundamental no sentido de se buscar a efetiva responsabilidade socioambiental por parte dos atores sociais atuantes no setor.

Palavras-chave profissional de saúde; saúde ambiental; formação de recursos humanos; meio ambiente.
Abstract This article presents the view health area professionals and students have concerning the interface between health and the environment. It is a qualitative, descriptive study undertaken with different social players that are part of the vocational training process in the health care area in a municipality in Rio Grande do Sul, Brazil. The data were collected through a semi-structured interview comprising guiding questions on the study subject and carried out among hospital workers, nurses, health care professors and students, and community health agents. Each subproject was analyzed individually based on the content analysis framework. The results show that the subjects have dichotomous views on the environment and acknowledge the adverse effects of the current environmental crisis, claiming that human beings are the main cause of it. The study subjects understand that there is a narrow interface between health and the environment and that the economically less privileged populations are those most affected by environmental damage. It is concluded that deepening the debate on the subject in the process of providing training and professional practice in health is fundamental in order to seek effective socioenvironmental responsibility among the social players involved in the sector.

Keywords health care professional; environmental health; training of human resources; environment. 


\section{Introdução}

A sociedade experimenta, atualmente, um processo de intensas e rápidas transformações. Diversos fatores de ordem política, econômica e cultural, dentre outras, contribuem para a configuração de um contexto social peculiar. Uma questão exemplar desse processo é o atual contexto de crise ambiental, que tem suscitado debates entre diversos segmentos sociais.

Dadas as proporções dessa crise, sabe-se que ela exige, para além do envolvimento de políticos e governantes, um comprometimento de indivíduos e coletividade, posto que invade diferentes espaços e cenários do cotidiano e atinge a todos, indiscriminadamente. É essa a ideia que dá configuração à concepção de 'sociedade de risco' e de 'modernidade reflexiva' em Beck (1997) e Giddens (1991), que afirmam sermos impactados por diferentes riscos os quais, muitas vezes, não podemos prever e controlar, por não serem localizados, mas sim disseminados globalmente. De acordo com os autores citados acima, esses riscos, fruto das consequências imprevistas do avanço técnico-científico e econômico ocorrido numa primeira etapa da modernidade, exigem hoje que os indivíduos se posicionem e ajam de acordo com novas bases e valores.

Embora diferentes setores da sociedade tenham relação com a problemática ecológica, o que se percebe é que algumas áreas do conhecimento e campos de atuação ainda têm uma aproximação muito tímida com a questão. Um dos campos que pode ser mencionado, e que se encontra nesse último caso, é o da saúde, na medida em que apenas em poucos espaços são visíveis discussões acerca da interface saúde e meio ambiente. Essa constatação reveste-se de maior importância ainda quando se sabe, segundo Freitas (2003), que problemas ambientais são, simultaneamente, problemas de saúde. Esse aspecto, além de vincular diretamente a crise ambiental ao setor saúde, também dá margem à interrelação com uma série de outras questões, tendo em vista a amplitude da crise ecológica e as múltiplas interfaces que daí advêm.

Desde o final da década de 1990, o governo brasileiro, por meio do Ministério da Saúde, tem buscado alavancar o debate sobre o tema, bem como desenvolver ações compatíveis com as necessidades do setor de saúde. Para isso, foram criados não apenas alguns órgãos, com o fim de estruturar, principalmente, a área de vigilância ambiental em saúde, mas também um aparato legislativo que visa adequar os serviços de saúde à necessidade de minimizar eventuais danos ambientais provenientes dos rejeitos dos mesmos. Contudo, essas ações ainda são isoladas e não contam com uma maior aderência dos diversos cenários e dos diferentes atores sociais que compõem o setor saúde.

No que tange à produção científica sobre o assunto, Freitas (2005), com base em amplo levantamento bibliográfico, indica haver o predomínio de uma 
noção de saúde pautada no modelo biológico do processo saúde-doença, o que resulta em enfoques epidemiológicos ou direcionados à avaliação de risco/exposição. Estudo semelhante (Camponogara, Kirchhof e Ramos, 2008) reitera que a produção científica nacional sobre saúde e meio ambiente está amparada predominantemente na pesquisa epidemiológica sobre os diferentes tipos de vetores que causam agravos à saúde da população, relacionados a doenças transmissíveis reemergentes (dengue, malária, febre amarela, dentre outras) que compõem o quadro de morbimortalidade do país e são atribuídas também ao desequilíbrio ecológico. Além disso, é possível verificar que os estudos, em sua maioria reflexões teóricas, buscam evidenciar lacunas na proposição e efetivação de políticas públicas sobre o tema. A discussão acerca da importância desse debate na formação e na prática profissional em saúde é, praticamente, inexistente.

De forma geral, defende-se a necessidade urgente de se ampliar o debate sobre a interface saúde e meio ambiente, uma demanda contemporânea que exige do setor saúde o estabelecimento de bases teóricas e práticas compatíveis com pressupostos éticos relacionados à responsabilidade com a preservação do planeta para esta e para as futuras gerações. A tematização dessa interface a partir do cenário da formação e da prática profissional parece imprescindível, uma vez que são os atuais e os futuros profissionais da saúde os atores sociais responsáveis pela materialização de quaisquer ações nesse sentido. Assim, é essencial a busca de conhecimentos sobre a visão desses sujeitos e sua capacidade de ação, bem como sobre eventuais fatores que interfiram nessa relação, a fim de se debaterem e problematizarem questões relacionadas ao tema, o que pode resultar em subsídios para a atuação profissional.

Tendo como base essas considerações, buscou-se desenvolver um estudo orientado pela seguinte questão de pesquisa: qual a visão de profissionais e estudantes da área da saúde sobre a interface saúde e meio ambiente? E seu objetivo geral é conhecer a visão de profissionais e estudantes da área da saúde acerca da interface saúde e meio ambiente.

\section{Metodologia}

Trata-se de um estudo, orientado pela abordagem qualitativa, cujos dados foram coletados por meio de subprojetos, junto de diferentes atores sociais8 que compõem a área da saúde - instituições públicas de saúde e instituições de ensino de saúde - em um município do interior do Rio Grande do Sul.

Cada subprojeto foi direcionado à investigação de uma instituição e/ou de atores sociais diferentes. Neste trabalho, serão apresentados dados de quatro subprojetos, direcionados à investigação do tema com trabalhadores 
hospitalares, docentes enfermeiros, acadêmicos da área da saúde e agentes comunitários de saúde. Outros subprojetos direcionados a investigar a concepção de outros profissionais da área da saúde ainda estão em andamento.

Na primeira etapa, classificada como diagnóstica, foram coletados dados relativos à temática com os seguintes sujeitos: 21 trabalhadores de uma instituição hospitalar pública de grande porte ( 3 enfermeiros, 6 técnicos de enfermagem, 3 médicos, 1 fisioterapeuta, 4 serventes de limpeza, 4 trabalhadores de áreas administrativas e de apoio); 6 docentes enfermeiros de uma instituição pública de ensino superior; 24 acadêmicos que cursavam o último ano da graduação de cursos da área da saúde de uma instituição pública de ensino superior; e 12 agentes comunitários de saúde, vinculados a equipes de saúde da família.

Os dados apresentados aqui foram coletados durante os anos de 2008 a 2010. Todos tiveram como técnica de coleta de dados entrevistas semiestruturadas com questões norteadoras semelhantes, versando sobre a temática geral do projeto relativa à visão dos sujeitos acerca do meio ambiente, da atual problemática ambiental, do desenvolvimento de ações de preservação ambiental, da interface saúde e meio ambiente, da abordagem da temática no processo formativo e laboral e da responsabilidade ambiental. Todos os dados foram coletados por enfermeiros e acadêmicos de enfermagem integrantes do Grupo de Pesquisa Trabalho, Saúde, Educação e Enfermagem, registrado na plataforma do Conselho Nacional de Desenvolvimento Científico e Tecnológico (CNPq), sub-linha Enfermagem, Saúde e Meio Ambiente, previamente treinados para a atividade.

Ao todo participaram do estudo 63 sujeitos, que foram entrevistados em local próprio (reservado e livre de movimentação) durante o período de trabalho ou de atividade acadêmica. Os sujeitos foram selecionados aleatoriamente (por sorteio), sendo considerados critérios de inclusão: atuar há pelo menos um ano no setor; ter vínculo empregatício definitivo; e, no caso dos acadêmicos, estar cursando o último ano do curso de graduação. As entrevistas foram gravadas e, posteriormente, transcritas pelos pesquisadores, compondo o corpus de análise do estudo. O encerramento da coleta de dados de cada subprojeto obedeceu ao critério de saturação teórica (Fontanella, Ricas e Turato, 2008). Os sujeitos foram identificados de acordo com o curso de graduação ou categoria profissional e o número da entrevista.

Os dados foram analisados em momentos distintos mediante o referencial proposto por Bardin (2007) sobre análise de conteúdo. Num primeiro momento, os dados de cada subprojeto foram analisados individualmente, obedecendo as seguintes etapas: organização do material e realização da pré-analise (leitura flutuante dos achados); organização de categorias de análise (com base em leitura aprofundada do material); e análise interpretativa, com interpretação dos autores e discussão com a literatura pertinente. Na 
sequência, procedeu-se ao cruzamento de informações obtidas nos diferentes subprojetos, buscando-se linhas de convergência entre as manifestações expressas pelos diferentes sujeitos.

Cada subprojeto foi submetido à aprovação institucional e ao Comitê de Ética em Pesquisa da instituição sede da investigação. A coleta de dados teve início somente após a tramitação nessas instâncias. Os sujeitos foram convidados a participar do estudo, e a entrevista foi realizada após a leitura e a assinatura do termo de consentimento livre e esclarecido. Dessa forma, o estudo obedeceu aos preceitos contidos na resolução n. 196/1996 do Conselho Nacional de Saúde sobre pesquisa com seres humanos.

\section{Resultados e discussão}

A seguir estão apresentados os principais resultados obtidos até o momento, que configuram importantes pontos de discussão e permitem reflexões sobre a abordagem da temática no processo de formação e prática profissional na área da saúde.

A análise dos dados permitiu verificar que, quando questionados sobre a sua concepção a respeito do tema, os sujeitos investigados têm visões dicotômicas sobre o meio ambiente. Embora para alguns profissionais e acadêmicos prevaleça a ideia de meio ambiente como espaço de interação entre os aspectos social e natural, ainda é marcante em outros uma visão naturalizada do meio ambiente. Nesse caso, os respondentes, quando questionados, relacionam o meio ambiente com a natureza de forma dissociada do contexto social.

Ah, natureza, me vem o ar puro, o verde lá de fora (Técnica de enfermagem, 12).

Ah! É a natureza. A natureza... Água, árvore, chuva, sol, não é? (Servente de limpeza, 15).

Toda a questão da natureza, da parte ecológica (...), a questão do ar, das árvores, tudo o que envolve a natureza. Meio ambiente voltado a isso: água, luz, sol, água, tudo voltado ao que for da natureza (Enfermeira assistencial, 1).

É todo o conjunto, no caso da natureza, ar, atmosfera, é isso aí... Em geral, rios, matas... (Agente comunitária de saúde, 12).

Para mim, quando penso no meio ambiente, penso na natureza, nos animais, em todo o ecossistema, nas plantas, nas árvores (Acadêmica de fonoaudiologia, 2). 
Como é possível perceber, esses depoentes tem uma visão de que o meio ambiente está, diretamente, relacionado com a natureza, no sentido de ser ambiente natural. De acordo com Giddens (1997), o termo 'natureza' tem sido utilizado com o significado de algo que está imperturbado, separado da intervenção humana. Em concordância, Carvalho (2004) argumenta que essa imagem de natureza não é objetiva e neutra, uma vez que influencia o conceito de meio ambiente disseminado no conjunto da sociedade. Essa visão 'naturalizada' tende a ver a natureza como ordem biológica, boa, equilibrada e estável, que existe independentemente da interação com o mundo cultural humano. Carvalho reitera que, embora não seja a única, essa concepção encontra-se fortemente inscrita no ideário ambiental da sociedade e está carregada de valores sócio-históricos. Em consequência, reduz o meio ambiente a apenas uma de suas dimensões, ficando fora do horizonte de compreensão o caráter interativo e de interdependência com a cultura humana, o que impede que se vislumbre, com maior abrangência, não só a problemática ecológica como também as suas soluções.

De acordo com Giddens (2002), uma das questões que define a modernidade é o que ele chama de segregação da experiência, fruto do pensamento positivista, que procurou eliminar os julgamentos morais e os critérios estéticos da vida moderna. Com isso, processos de segregação moral aparecem em várias áreas, removendo ou ocultando questões existenciais da vida diária. A concepção da natureza participa da segregação da modernidade, estando vinculada à sociedade apenas por meio de uma relação instrumental de controle e uso. Em colaboração com essa ideia, Santos (2006) argumenta que a natureza tem sido tomada com um lugar de inferioridade e exterioridade; um lugar que não está em posição de igualdade com o 'mundo humano'. Isso explica, também, a noção da superioridade do ser humano em relação aos demais seres que tem permeado, historicamente, as relações entre ambos, reforçando a lógica antropocêntrica.

Nesse sentido, urge reconhecer que a problemática ambiental precisa ser apreendida por meio de uma visão complexa de meio ambiente, na qual a natureza integre uma rede de relações, não apenas naturais, mas também sociais e culturais (Carvalho, 2004). Para Maturana (1997), as novas demandas advindas destes tempos contemporâneos requerem práticas sociais que concebam a sociedade e a natureza de forma interligada e interdependente, não no sentido de dependência, mas de interconstituição.

Dessa ótica, também surgiu, entre os diferentes atores sociais entrevistados, uma visão de interrelação entre os mundos social e natural, revelando uma ideia de interação ser humano e meio ambiente:

É tudo [o meio ambiente]. É dentro e fora do hospital. Nossos rios, árvores, florestas. Tudo. Nós aqui dentro também somos meio ambiente (Enfermeira assistencial, 3). 
É onde a gente tem o meio para viver, e esse meio nós temos que conservar ou manter da melhor forma possível, para ter um equilíbrio: eu e o meio. (...) Então, tudo se associa, tudo está interligado ao meio ambiente, aos bem ou aos malcuidados (Técnica de enfermagem, 9).

Eu penso que é tudo o que envolve o meio em que a gente vive. Por exemplo, a natureza, a comunidade, tudo é o meio ambiente (Agente comunitária de saúde, 11).

Eu entendo o meio ambiente não só como você está lá e eu estou aqui. Eu estou dentro deste meio ambiente, eu faço parte do meio ambiente. Eu não posso estar separado, senão eu vou estar dentro de uma visão cartesiana, até fragmentada. Eu estou aqui neste meio ambiente, eu faço parte deste meio ambiente, e eu posso agregar pontos positivos a este meio ambiente ou não, depende da forma como eu agir e como eu interagir com esse meio (Enfermeira docente, 4).

Bom, meio ambiente para mim é o lugar ou é o meio em que a gente convive, e isso inclui todos os aspectos que influenciam diretamente a nossa vida. A gente tenta relacionar meio ambiente com a natureza, mas eu acredito que seja muito mais do que isso: é o meio social - é o meio natural, sim -, mas tem outros aspectos que também influenciam diretamente na nossa vida (Acadêmica de fisioterapia, 1).

Como é possível verificar, alguns entrevistados parecem ter uma visão diferente da concepção dos demais, uma vez que incluem em seus depoimentos certa relação entre o que é considerado, a priori, do mundo natural e outros elementos atinentes a aspectos sociais e tipicamente vinculados ao meio socialmente construído pelos seres humanos.

De acordo com Floriani (2006), pensar de forma integrada a respeito da natureza e da sociedade não é uma tarefa fácil, simples e imediata, tendo em vista que a história da ciência, nos últimos duzentos anos, privilegiou a disjunção, o controle e a fragmentação da natureza, da sociedade e do ser humano. Beck (1997) concorda que as questões ecológicas precisam ser vistas de forma mais interativa; no entanto, a palavra 'ambiente' ainda soa como um contexto externo à ação humana, embora já não se encontre alheio à vida social, sendo, ao contrário, completamente penetrado e reordenado por ela. Assim, Beck acredita que, atualmente, o 'natural' se encontra intrincadamente confundido ao 'social', e a crise ecológica abre um leque de discussões e ações, obrigando os seres humanos a tomarem decisões práticas e éticas. Com isso, surge a necessidade de pensar a relação sociedade-natureza de forma mais integrada.

Com um enfoque mais voltado para a questão ética implícita a essa relação, Jonas (1995) afirma que a natureza alberga valores e tem um fim, o que implica a obrigatoriedade de uma relação equânime, de respeito, entre 
o ser humano e o mundo natural, posto que a vida é o fim ou um dos principais fins da natureza. Nesse sentido, Jacobi (2006) reitera a necessidade da internalização da questão ambiental, num esforço de fortalecer visões integradoras que estimulem uma reflexão em torno da diversidade e da construção de sentidos nas relações indivíduo-natureza, dos riscos ambientais globais e locais e das relações ambiente-desenvolvimento.

Nesse sentido, depreende-se que o estabelecimento de qualquer discussão no campo da saúde acerca da interface saúde e meio ambiente precisa contemplar também o debate sobre a concepção de meio ambiente. Obviamente, a busca por uma visão mais integradora entre as dimensões social e natural deve ser a pretendida, no intuito de fomentar-se o desenvolvimento de uma práxis em saúde que contemple o meio ambiente como inerente ao processo de viver humano e, em consequência, do processo saúde-doença.

\section{O impacto da atual problemática ambiental}

Ao serem questionados sobre sua concepção a respeito da atual problemática ambiental, os sujeitos manifestaram, em seus depoimentos, além de certo impacto diante da atual problemática ambiental, uma menção ao ser humano como principal agente causal dos danos ambientais. Há a evidência também de que a obtenção de informações sobre o tema se dá por meio da mídia, tendo em vista que revelam não haver uma abordagem aprofundada sobre o assunto nos cursos de graduação ou nos espaços de trabalho. Com isso, não se verifica uma reflexão mais aprofundada sobre o tema, pois muitos remetem a solução da questão para as esferas governamentais. Isso é corroborado ainda pelo fato de muitos manifestarem que não desenvolvem, em seu cotidiano doméstico, ações de preservação ambiental.

Os depoimentos a seguir são exemplares das manifestações de impacto diante da atual problemática ecológica:

Geralmente, quando fala em meio ecológico a gente já pensa mais na destruição que está ocorrendo (Técnica de enfermagem, 12).

Não sei se é porque a mídia está falando mais, mas o que vem mais à mente é o problema do aquecimento global. Do fim da Amazônia, que já estão prevendo para alguns anos. Da quebra do que seria nossa maior riqueza praticamente. (...) Na verdade, estão muito interligados o fim da Amazônia, a destruição das matas, a poluição de rios, com o aquecimento da água, do solo, (...) a temperatura (Fisioterapeuta, 20).

Ele [meio ambiente] está sendo afetado no seu todo, no ar que respiramos, no assoreamento dos rios, nas chuvas torrenciais que antes não aconteciam, nos 
vendavais. Isso é uma resposta que o meio ambiente está dando ao mau uso dos homens. Se não houver uma conscientização das pessoas que também fazem parte desse meio ambiente, para mim, se não houver uma consciência mais crítica, mais ecológica de que cada um tem o seu papel na conservação desse ambiente, a Terra realmente vai acabar (Enfermeira docente, 1).

A problemática ambiental, ela é muito pior do que a gente imagina, eu acredito nisso, porque a gente se relaciona diretamente com a natureza, porque, sempre que se fala em meio ambiente, vem à tona a questão da natureza, mas esse é um aspecto que está sendo abordado, é apenas um dos aspectos abordados. Diríamos assim, é um problema do qual nós somos culpados, todas as pessoas são culpadas, o sistema é culpado, a tecnologia é culpada. E todo o avanço, tudo aquilo que tem certo avanço ou progresso, ou evolução - e essa evolução pode ser positiva ou não - tem uma consequência e, infelizmente, todo o meio está sendo alterado em função disso (Acadêmico de fisioterapia, 3).

Pois é, hoje, principalmente no nosso país, vivemos voltados para o progresso, para a criação de novas indústrias, para o emprego, para uma melhor qualidade de vida, só que isso tem um custo. Tudo o que a gente faz para melhor, a gente tem que fazer com responsabilidade. Não é só pegar lá e fazer, criar e não dar bola para o resto, pois isso vai voltar para a gente também (Acadêmico de medicina, 4).

As expressões acima demarcam um processo de maior sensibilização para a problemática ambiental, motivada, principalmente, pelo enfrentamento dos perigos advindos da destruição ambiental em geral. Os sujeitos sofrem o impacto dos problemas ambientais, em sua maioria veiculados pela mídia; contudo, isso não necessariamente se refletirá em uma maior agilidade no desenvolvimento de ações de preservação ambiental. Essas expressões retratam bem o conceito de sociedade de risco e reflexividade. "No autoconceito da sociedade de risco, a sociedade torna-se reflexiva (no sentido mais estrito da palavra), o que significa dizer que ela se torna um tema e um problema para ela própria" (Beck, 1997, p. 19). No entanto, o mesmo autor alerta que a palavra reflexiva não significa reflexão, mas sim autoconfrontação - no caso, com os efeitos da sociedade de risco. Beck alega que o fato de ela vir a se tornar, posteriormente, objeto de reflexão (pública, política e científica) não deve obscurecer o mecanismo não refletido e quase autônomo de transição: é exatamente a abstração que produz e proporciona realidade à sociedade de risco.

Para Giddens (1991), a reflexividade é definidora de toda ação humana. A modernidade é constituída pelo, e por meio do, conhecimento reflexivamente aplicado, mas esse conhecimento traz consigo não mais a certeza presumida pelas antigas instituições, e sim uma sensação de insegurança, 
tendo em vista os efeitos danosos advindos do progresso, de que surgem os riscos que dão configuração à chamada sociedade de risco. Contudo, apesar de, num primeiro momento, a reflexividade não se constituir em reflexão, ela proporciona uma discussão sobre saberes e práticas e convida ao diálogo reflexivo, transformando-os de maneira coerente com as demandas da sociedade.

No caso da problemática ambiental, essa discussão pode possibilitar a emergência de novos sentidos e significados, de um modo diferente, plural e complexo de pensar a relação ser humano-sociedade-natureza. “O mundo da reflexividade desenvolvida, em que a interrogação das formas sociais torna-se lugar-comum, é um mundo que em muitos casos estimula a crítica ativa" (Beck, 1997, p. 9).

De acordo com Floriani (2006), resta-nos a expectativa de que, dessa crise intelectual e ética sobre como o mundo é fabricado e entendido, possam emergir outras formas de se pensar a relação sociedade-natureza e de atuar sem comprometer ainda mais o presente e o futuro. De nada serve ter consciência das incertezas somente para saber. Os indícios de que estamos diante de grandes perigos já são suficientes para mobilizar uma nova forma de apreendê-los e de ação.

Diante disso, quando questionados sobre quem seria ou o que causaria toda a problemática ambiental, é marcante nos entrevistados a ideia do ser humano como agente causal da destruição ambiental:

Eu acho que tudo isso que está acontecendo - a questão do desmatamento da floresta amazônica, o efeito-estufa-, (...) é decorrência das próprias consequências do homem. Dos próprios efeitos dele mesmo. É ele que está provocando isso. É ele que está fazendo desmatamento, é ele que não está tendo controle da questão da água, que está extrapolando, utilizando a natureza de forma errada (Enfermeira assistencial, 3).

Primeiro é o 'eu', segundo a sociedade e depois vêm todos os governantes que não tomam atitude e que, se tomam, de modo geral não fiscalizam. Mas começa por mim: eu uso o carro, consequentemente todo mundo vai usar o carro. Então isso é um problema que vai começar comigo. E quem é que vai segurar isso, da utilização do carro, vai largar carbono, vai poluir o meio ambiente (...). A água, no caso, também é um problema. O pessoal não cuida da água, esbanja, lava carro, utiliza mais do que o necessário (Técnica de enfermagem, 6).

Eu acredito que o ser humano é um dos grandes contribuintes para todos os problemas ambientais que estão acontecendo: a gente tem (...) gases estufa, a gente tem problemas relacionados a indústrias que são grandes poluentes, com agrotóxicos e [produtos] químicos que invadem os rios. E a gente está vendo esse problema 
que está muito forte em relação a El Niño, La Niña e isso. A gente está vendo toda essa problemática de temporais, tempestades, que estão destruindo todos os litorais, acabando com o que a gente tem na natureza (Acadêmica de Enfermagem, 1).

As pessoas poluem, degradam o meio ambiente e a natureza sem pensar nas consequências, no futuro de tudo isso, de toda a poluição, de todo o desmatamento, de secar rios, de jogar lixo, e essa ganância do homem por dinheiro vem destruindo toda a natureza, sem que ele pense no depois (Acadêmica de Fisioterapia, 3).

Eu acho que tudo isso surgiu da necessidade do ser humano de transformar o meio em que vive para adaptá-lo e das necessidades que surgiram, como o aumento da população. Com toda a história da Revolução Industrial, começou a aumentar muito a produção, fomos obrigados a achar uma maneira, subterfúgios, para conseguir viver melhor... (Acadêmico de Medicina, 5).

Diante do exposto, depreende-se que, para os respondentes, o grande causador dos problemas ambientais é o ser humano. Contudo, chama a atenção o fato de poucos sujeitos incluírem-se nesse contexto, o que nos faz pensar que a responsabilidade sobre os danos ambientais está sendo atribuída aos outros. Essa visão pode ter um impacto considerável no desenvolvimento ou não de ações de preservação ambiental, uma vez que, apesar de terem ciência de que vivenciamos os efeitos da crise ambiental, a responsabilidade pela sua resolução também pode estar sendo transferida para os outros, incluindo-se aí os governantes.

As suspeitas de que o ser humano seria o agente responsável pelo aquecimento global foram confirmadas recentemente, em 2007, no Painel Intergovernamental sobre Mudanças Climáticas (IPCC, do inglês Intergovernmental Panel on Climate Change), por meio dos relatórios que registram as vulnerabilidades do planeta e projetam impactos para o próprio ser humano e para o planeta. Em concordância, Berlinguer (2004) ressalta que são as escolhas humanas as grandes responsáveis pelos fenômenos de destruição ambiental, que são resultado de escolhas individuais e coletivas e sobre diretrizes econômicas, sociais, culturais e de valores. Demarca que, por isso, os fenômenos de destruição ambiental são modificáveis com base em ações voluntárias, ditadas tanto pela necessidade quanto pela consciência.

Nesse sentido, Jonas (1995) atribui ao agir humano grande responsabilidade. Considerando-se que o homem é o propulsor da destruição que vivenciamos, é também ele o único que possui a liberdade e a responsabilidade de agir em prol da natureza, entendendo que ela não é um valor de uso, e sim que ela tem um fim em si mesma. De certa forma, essa visão se relaciona com a reflexividade inerente aos tempos contemporâneos e com a possibilidade de reorientar práticas sociais mediante uma postura crítica em 
relação a essas mesmas práticas, conjugadas com o retorno das questões morais e existenciais, conforme propõe Giddens (2002).

Contudo, contemporaneamente, ainda parecemos imersos em um contexto de inebriamento: sofremos o impacto dos problemas ambientais, mas, ao mesmo tempo, somos tomados por uma espécie de imobilismo, motivado por um sentimento de impotência perante as grandes questões existenciais que o modernismo segregou de nossas experiências cotidianas. Além disso, conforme afirma Pelizzoli (2004), nossa subjetividade foi cooptada pelo anseio do saber e do poder, sendo vista apenas como mente racional e corpo, e não como parte de um sistema integrado, interdependente e simbólico. “Percebe-se nitidamente hoje a disparidade gritante entre o desenvolvimento científico e tecnológico por um lado e o atraso em termos de sabedoria, espiritualidade e ética por outro" (Pelizzoli, 2004, p. 64).

É com base nisso que Jonas (1995) atribui imensa responsabilidade ao sujeito, pois, independentemente da qualidade moral existente na relação entre o eu e o mundo, essa responsabilidade não pode ter outra origem a não ser o próprio eu. Por isso, só uma ética fundamentada na amplitude do ser, e não apenas na singularidade ou na peculiaridade do ser humano, é que pode ser de importância no universo das coisas. Nesse sentido, Bauman (2007) enfatiza que todas as decisões que o ser humano toma em seu ambiente social têm significado ético e representam um impacto sobre as outras pessoas, mesmo quando só pensamos no que ganhamos ou perdemos com o que fazemos, e alerta que, na era midiática, com extensão planetária, não é possível dizer "eu não sabia" como desculpa para a inação.

\section{Interface saúde e meio ambiente}

Ao se explorar as concepções dos sujeitos sobre saúde e meio ambiente, chama a atenção o fato de muitos relatarem uma estreita interface entre ambos.

Saúde e meio ambiente estão completamente relacionados, até porque a gente sabe que a nossa saúde depende do lugar em que a gente vive, depende da nossa qualidade de vida (Acadêmica de Enfermagem, 1).

Estão diretamente relacionados [saúde e meio ambiente], não consigo discernir esses dois tópicos (...). A saúde está diretamente relacionada com as condições, com o meio ambiente no qual estamos inseridos, a questão de um ar limpo, despoluído, a questão da qualidade da água que se utiliza, a questão da qualidade do solo do qual vem o alimento (...), estão diretamente relacionadas (Acadêmica de Fisioterapia, 4). 
Saúde e meio ambiente têm uma interligação, existe uma interligação entre essas duas coisas: não tem como ter saúde num ambiente poluído, são coisas que andam juntas. Se você não tem um ambiente arborizado, bem arejado, com a fauna e a flora preservadas, consequentemente a sua saúde vai estar prejudicada (...) (Acadêmico de Medicina, 4).

Estão extremamente ligadas porque a saúde é promovida a partir de condições ambientais saudáveis, e onde há desequilíbrio de um, desequilibra a outra também. Várias coisas do ambiente quando não adequadas promovem doenças (Enfermeira docente, 2).

O meio ambiente influi na saúde: se o meio ambiente não está bem também, a minha saúde não vai estar bem. Ele influi diretamente (Agente comunitária de saúde, 6).

Os sujeitos entendem que existe uma ligação direta entre saúde e meio ambiente, ressaltando que muitas doenças ocorrem como resultado de problemas ambientais. No entanto, para os entrevistados, as populações menos favorecidas economicamente - por exemplo, as que habitam em locais sem saneamento - são as mais predispostas à ocorrência de doenças, evidenciando uma clara correlação entre saúde, meio ambiente e pobreza.

Eu percebo que isso [a relação meio ambiente e saúde] tem a ver com a mudança de perfil epidemiológico. É uma influência direta, remetendo mais ao contexto da cidade grande. A gente vê a situação das periferias, que tem uma condição muito precária de vida, de saneamento, de esgoto e de meio ambiente mais degradado... Isso vai comprometer a saúde deles, porque eles podem cair, ter contato com esse lixo, se contaminar de alguma maneira (Acadêmica de Enfermagem, 6).

Isso é muito básico, o problema ambiental. Pessoas que têm um nível mais precário de saneamento estariam mais sujeitas a essas mudanças. A gente atende muito a população pobre, sabe dos problemas que ela tem e sabe que estão muito relacionados ao meio em que vive (...) (Médico, 1).

(...) se a pessoa está em um ambiente que não é adequado, não tem higiene, não tem condições básicas de higiene e de saneamento, isso influencia diretamente na saúde e vemos isso todo o tempo no dia a dia da faculdade. Existe essa relação direta, meio ambiente negativo, em condições precárias, igual à saúde precária. Já se você vive em um ambiente mais adequado, com higiene, com condições adequadas, a saúde da pessoa vai ser melhor. Então, a primeira coisa que me vem em relação a essas duas coisas, meio ambiente e saúde, é que isso é diretamente proporcional (Acadêmico de Fisioterapia, 5). 
A saúde das pessoas está muito relacionada ao ambiente no qual elas vivem. Quando o ambiente é, por exemplo, muito miserável, naqueles lugares que têm muito lixo perto, a saúde delas está sendo prejudicada, há mais riscos ainda quando não se tem um ambiente favorável (Acadêmica de Fonoaudiologia, 3).

Acho que a saúde está ligada diretamente ao meio ambiente, porque, dependendo do lugar onde você mora, dependendo das condições do local onde você vive, onde tem esgoto a céu aberto não é a mesma coisa de onde é tudo encanadinho, não tem os bichos que levam doenças e tal... Acho que interfere completamente na saúde... (Acadêmico de Odontologia, 3).

Como se percebe, os sujeitos manifestam claramente que o adoecimento da população em decorrência de problemas ambientais tem vinculação com o seu nível socioeconômico, estando os mais pobres mais sujeitos não só a diferentes agravos, como também ao acesso mais restrito à assistência à saúde.

De acordo com Beck (1997), com o advento da sociedade de risco surgem conflitos relacionados à distribuição dos malefícios dela oriundos, desencadeando discussões sobre como podem ser distribuídos, evitados, controlados e legitimados. Berlinguer (2004), ao abordar essa questão, remete para o teor ético a ela implícito, alegando que, a despeito do progresso, registrado por muitos indicadores de saúde, no conhecimento e nas soluções possíveis das doenças e mortes evitáveis, também existe uma escassa intenção de usar esses conhecimentos e soluções no interesse de todos. Com isso, o autor busca alertar para o fato de as parcelas mais pobres da população serem menos beneficiadas com avanços científicos e tecnológicos, estando, ainda, mais sujeitas aos riscos decorrentes do progresso.

Rigotto e Augusto (2007) alertam que os riscos tecnológicos e ambientais gerados pelos processos de produção e consumo, bem como a degradação ambiental e os agravos à saúde que ela causa, são desigualmente distribuídos no espaço e entre a população. Assim, diversos segmentos sociais encontram-se mais vulneráveis a esses novos riscos, condição agravada por fatores como estado nutricional, escolaridade, acesso à informação e cobertura de políticas públicas. Para essas autoras, grupos sociais mais pobres estão mais sujeitos a problemas ambientais decorrentes de fontes locais; já os mais ricos ocupam áreas menos degradadas. Problemas como falta de saneamento básico e de coleta de lixo, poluição do ar, da água e da terra, levam à ocorrência de muitas doenças e deformações congênitas, que agravam a situação de saúde das populações mais pobres.

Há forte relação entre os problemas de saúde e a desigualdade social resultante do modelo econômico adotado por determinada sociedade, quando produtor de maior exclusão social, marginalização, empobrecimento e incapacidade de obter condições mínimas para uma satisfatória qualidade de vida. 
Em suma, se focalizamos a questão de forma ampla, temos que a totalidade da população está sujeita a riscos ambientais; contudo, quando associamos os fatores econômicos e sociossanitários, percebemos que, inevitavelmente os mais pobres são mais vulneráveis e desigualmente sujeitas a esses riscos.

De acordo com Berlinguer (2004), embora tenha crescido a consciência ambiental nas últimas décadas, o mesmo não aconteceu em relação à saúde. Acentuaram-se os riscos decorrentes das transformações negativas do meio ambiente, atingindo a todos, mesmo que em graus diversos para indivíduos, populações ou classes. Barreto e Carmo (2007) afirmam que, no Brasil, há imensas diferenças nos indicadores de saúde quando se comparam as populações pobre e rica, diferenças derivadas da concentração de riqueza e bens. Com isso, esses autores acreditam que a situação de pobreza em que vive parte da nossa população, aliada às intensas transformações por que vem passando a sociedade nas últimas décadas - urbanização, alterações do meio ambiente, desmatamento, ampliação de fronteiras agrícolas, processos migratórios, industrialização, desemprego, dentre outras constituem a base sobre a qual o Sistema Único de Saúde deve atuar.

A não observância dessa importante questão leva à ocorrência da super-posição de riscos, tanto de riscos urbanos, caracterizados pela deficiência de saneamento e habitação, quanto de riscos advindos da poluição ambiental, ou ocupacionais, ou, ainda, aqueles gerados pela 'modernização' das relações sociais etc. Para Barreto e Carmo (2007), os efeitos da globalização estão relacionados com questões muito diversas: aumento da desigualdade entre as nações, intensificação do comércio de drogas e aumento da temperatura global, gerando novos "riscos globais" e deteriorando enormemente as condições de saúde.

Esta superposição de fatores ambientais e sociais 'velhos' e 'novos' é que torna possível que algumas doenças infecciosas tradicionais sejam mantidas e que ocorra a emergência ou a reemergência de outras tantas, em paralelo ao aumento das doenças crônicas e das violências" (Barreto e Carmo, 2007, p. 1.788).

Dessa forma, percebe-se a importância do estabelecimento de políticas direcionadas à valorização da inter-relação entre o meio ambiente e a promoção da saúde e da qualidade de vida. A criação de ambientes favoráveis à saúde implica reconhecer a complexidade das sociedades e as relações de interdependência entre diversos setores, indo da proteção do meio ambiente, até o acompanhamento do impacto que as mudanças no meio ambiente produzem sobre a saúde, o que precisa ser mais enfatizado na agenda da área (Buss, 2000).

Com isso, depreende-se que a possibilidade de uma concepção de interface saúde e meio ambiente mais abrangente e que contemple os inúmeros aspectos que compõem o processo de viver saudável é um desafio. Nesse 
sentido, urge que se busque estabelecer uma pauta de discussões sobre a temática, a qual deve estar presente tanto nos cenários de formação e de prática profissional, visto que têm relação com concepções individuais e coletivas, quanto em instâncias formuladoras de políticas públicas.

\section{Conclusões}

Os dados oriundos dos diversos subprojetos apontam para algumas proposições que, acreditamos, devem ser contempladas nos processos formativos e de educação permanente na área da saúde, como forma de buscar-se a responsabilidade socioambiental por parte dos diferentes atores sociais que dão concretude e materialidade ao saber/fazer saúde.

Os resultados revelam existir uma visão unilateral acerca do meio ambiente por parte de alguns profissionais e estudantes da área de saúde, visão que relaciona o meio ambiente apenas com a natureza. Dessa forma, qualquer proposta de abordagem sobre o tema precisa incorporar um debate sobre o meio ambiente no sentido de favorecer uma percepção da indiscutível interação entre o mundo natural e aquele socialmente construído.

Além disso, urge o estabelecimento de estratégias de discussão que remetam os atores sociais à visualização dos efeitos da crise ambiental em seu cotidiano, sob pena de manterem uma postura de distanciamento em relação a isso. A ideia defendida aqui, e respaldada pela literatura, é a de que, uma vez confrontados com a atual problemática ambiental, os sujeitos precisam ser estimulados a refletir sobre a mesma, na tentativa de buscarem uma responsabilização que remeta ao desenvolvimento de ações de preservação ambiental. No que tange à área da saúde especificamente, pressupõe-se que a ampliação do debate sobre o tema, com um aprofundamento do processo reflexivo, oportuniza aos profissionais a condição de rever concepções, posturas e valores, no sentido de comprometê-los com a sustentabilidade ambiental.

Também merece destaque a questão da interface saúde e meio ambiente, que é percebida pelos sujeitos, porém com um olhar focalizado para as populações menos favorecidas socioeconomicamente, as quais estariam mais expostas aos riscos decorrentes dos problemas ambientais. Esse fato não deve ser negligenciado, uma vez que, embora possa haver maior exposição das populações mais pobres, somos todos afetados pelos danos decorrentes da problemática ambiental, independentemente da classe social. Por isso, é necessário que o debate sobre o tema inclua uma visão ampliada acerca da concepção de risco, sobretudo de risco ambiental, no sentido de possibilitar aos sujeitos a percepção da amplitude de situações decorrentes da problemática ambiental que afetam a todas as populações, indistintamente. 
A partir dessas considerações, tem-se a expectativa de buscar um maior engajamento dos profissionais da saúde com a sustentabilidade ambiental. Além disso, há a possibilidade de estabelecer um processo assistencial em saúde mais abrangente, no sentido de valorização do meio ambiente como uma dimensão essencial para o processo de viver humano e que contribui fundamentalmente para a promoção da saúde e da qualidade de vida das pessoas e populações.

A principal limitação deste estudo é o fato de serem parciais os dados nele apresentados. Contudo, acreditamos que eles já permitem tecer reflexões sobre o tema, no sentido de propor subsídios para o debate. Dessa forma, sugere-se o desenvolvimento de estudos que oportunizem a ampliação do olhar sobre a interface saúde e meio ambiente nos diferentes cenários em que se dá o processo de ensino e laboral na área da saúde, no intuito de familiarizar os atores sociais com a temática, de forma a torná-la aspecto indissociável do fazer saúde.

\section{Colaboradores}

Silviamar Camponogara é a responsável pela concepção da pesquisa, além de ter feito a análise de dados e a revisão do manuscrito. Os demais autores participaram na coleta e análise dos dados, bem como na redação do manuscrito.

\section{Notas}

1 Enfermeira e professora do Departamento de Enfermagem e do Programa de Pós-graduação em Enfermagem da Universidade Federal de Santa Maria (UFSM), Santa Maria, Rio Grande do Sul, Brasil. Doutora em Enfermagem pela Universidade Federal de Santa Catarina. <silviaufsm@yahoo.com.br>

Correspondência: Rua Visconde de Pelotas, 1.230, ap. 201, Centro, Santa Maria, Rio Grande do Sul, Brasil, CEP 97015-140.

2 Enfermeira e membro do Grupo Trabalho, Saúde, Educação e Enfermagem da Universidade Federal de Santa Maria (UFSM), Santa Maria, Rio Grande do Sul, Brasil. Graduada em Enfermagem pela Universidade Federal de Santa Maria. <cibellemelloviero@yahoo.com.br> 
3 Enfermeira e membro do Grupo Trabalho, Saúde, Educação e Enfermagem da Universidade Federal de Santa Maria (UFSM), Santa Maria, Rio Grande do Sul, Brasil. Graduada em Enfermagem pela Universidade Federal de Santa Maria. <gracieleerthal@gmail.com>

4 Enfermeira e membro do Grupo Trabalho, Saúde, Educação e Enfermagem da Universidade Federal de Santa Maria (UFSM), Santa Maria, Rio Grande do Sul, Brasil. Mestranda do Programa de Pós-graduação em Enfermagem da Universidade Federal de Santa Maria.<paolinha_diaz@hotmail.com>

5 Membro do Grupo Trabalho, Saúde, Educação e Enfermagem da Universidade Federal de Santa Maria (UFSM), Santa Maria, Rio Grande do Sul, Brasil. Graduanda em Enfermagem da Universidade Federal de Santa Maria. <gabriela_rossato@yahoo.com.br>

6 Enfermeira e membro do Grupo Trabalho, Saúde, Educação e Enfermagem da Universidade Federal de Santa Maria (UFSM), Santa Maria, Rio Grande do Sul, Brasil. Mestranda de Enfermagem da Universidade Federal de Santa Maria. <sgssm1@hotmail.com>

7 Enfermeiro e membro do Grupo Trabalho, Saúde, Educação e Enfermagem da Universidade Federal de Santa Maria (UFSM), Santa Maria, Rio Grande do Sul, Brasil. Mestrando de Enfermagem da Universidade Federal de Santa Maria. <roger_rrp@yahoo.com.br>

8 A denominação atores sociais, neste artigo, está apoiada no referencial sociológico, o qual reitera que, enquanto sujeitos contemporâneos, somos todos afetados pelos atuais problemas vivenciados na chamada sociedade de risco, independentemente da classe econômica a que pertençamos ou do nosso nível de formação (Beck, 1997).

\section{Referências}

BARDIN, Laurence. Análise de conteúdo. 4. ed. Lisboa: Edições 70, 2007.

BARRETO, Mauricio Lima; CARMO, Eduardo Hage. Padrões de adoecimento e de morte da população brasileira: os renovados desafios para o Sistema Único de Saúde. Ciência \& Saúde Coletiva, Rio de Janeiro, v. 12, sup., p. 1.779-1.790, 2007.

BAUMAN, Zygmunt. Vida líquida. Rio de Janeiro: Jorge Zahar, 2007.

BECK, Ulrich. A reinvenção da política: rumo a uma teoria da modernização reflexiva. In: __ ; GIDDENS, Anthony; LASH, Scott (Orgs.). Modernização reflexiva: política, tradição e estética na ordem social moderna. São Paulo: Editora Unesp, 1997. p. 11-71.

BERLINGUER, Giovanni. Bioética cotidiana. Brasília, DF: Editora UnB, 2004.

BRASIL. Ministério da Saúde. Conselho Nacional de Saúde. Resolução n. 196, de 10 de outubro de 1996. Fixa diretrizes e normas regulamentadoras de pesquisa envolvendo seres humanos. Brasília: Conselho Nacional de Saúde, 1996.

BUSS, Paulo Marchiori. Promoção da saúde e qualidade de vida. Ciência \& Saúde Coletiva, Rio de Janeiro, v. 5, n. 2, p. 163-177, 2000 . 
CAMPONOGARA, Silviamar; KIRCHHOF, Ana Lucia Cardoso; RAMOS, Flavia Regina Souza. Uma revisão sistemática sobre a produção científica com ênfase na saúde e meio ambiente. Ciência \& Saúde Coletiva, Rio de Janeiro, v. 13, n. 2, p. 427-439, 2008.

CARVALHO, Isabel Cristina Moura. Educação ambiental: a formação do sujeito ecológico. São Paulo: Cortez, 2004.

FLORIANI, Dimas. Ciências em trânsito, objetos complexos: práticas e discursos socioambientais. Ambiente \& Sociedade, Campinas, v. 9, n. 1, p. 65-80, jan.-jun. 2006.

FONTANELLA, Bruno Jose Barcelos; RICAS, Janete; TURATO, Egberto Ribeiro. Amostragem por saturação em pesquisas qualitativas em saúde: contribuições teóricas. Cadernos de Saúde Pública, Rio de Janeiro, v. 24, n. 1, p. 17-27, 2008.

FREITAS, Carlos Machado de. A produção científica sobre o ambiente na saúde coletiva. Cadernos de Saúde Pública, Rio de Janeiro, v. 21, n. 3, p. 679-701, maio-jun. 2005.

Problemas ambientais, saúde coletiva e ciências sociais. Ciência \& Saúde Coletiva, Rio de Janeiro, v. 8, n. 1, p. 137-150, 2003.

GIDDENS, Anthony. A vida em uma sociedade pós-tradicional. In: BECK, Ulrich; GIDDENS, Anthony; LASH, Scott (Orgs.). Modernização reflexiva: política, tradição e estética na ordem social moderna. São Paulo: Editora Unesp, 1997. p. 73-134.
As consequências da modernidade.

São Paulo: Editora Unesp, 1991.

Modernidade e identidade. Rio de Janeiro: Jorge Zahar, 2002.

INTERGOVERNMENTAL PANEL ON CLIMATE CHANGE (IPCC). Fourth Assessment Report: Climate Change. Cambridge, Inglaterra: Cambridge University Press, 2007.

JACOBI, Pedro. Educação ambiental e o desafio da sustentabilidade socioambiental. O Mundo da Saúde, São Paulo, v. 30, n. 4, p. 524-531, out.-dez. 2006.

JONAS, Hans. El principio de responsabilidad: ensayo de una ética para la civilización tecnológica. Barcelona: Herder, 1995.

MATURANA, Humberto. A ontologia da realidade. Belo Horizonte: UFMG, 1997.

PELIZZOLI, Marcelo Luiz. A emergência do paradigma ecológico: reflexões ético-filosóficas para o século XXI. 2. ed. Petrópolis: Vozes, 2004.

RIGOTTO, Raquel Maria; AUGUSTO, Lia Giraldo. Saúde e ambiente no Brasil: desenvolvimento, território e iniquidade social. Cadernos de Saúde Pública, Rio de Janeiro, v. 23, sup. 4, p. 475-501, 2007.

SANTOS, Boaventura Sousa. A gramática do tempo: para uma nova cultura política. São Paulo: Cortez, 2006.

Recebido em 20/09/2011

Aprovado em 02/10/2012 